\title{
PREVALENCE AND COMMONEST CAUSES FOR OTITIS EXTERNA IN DOGS FROM TWO POLISH VETERINARY CLINICS
}

\author{
N. ŚWIĘCICKA, H. BERNACKA, E. FAC \& J. ZAWIŚLAK \\ Department of Sheep, Goat and Fur Bearing Animal Breeding; Faculty of \\ Animal Breeding and Biology, Bydgoszcz, Poland
}

\begin{abstract}
Summary
Święcicka, N., H. Bernacka, E. Fac \& J. Zawiślak, 2015. Prevalence and commonest causes for otitis externa in dogs from two Polish veterinary clinics. Bulg. J. Vet. Med., 18, No 1, $65-73$.

The aim of this research was to determine the incidence of otitis externa in dogs from two veterinary clinics in Poland caused by fungi, bacteria and parasites, taking into consideration predisposing factors as breed or season of the year. The research material was based on the data collected from dogs with otitis externa symptoms. A total of 1,185 dogs were registered, 121 of them were diagnosed with otitis externa. It was observed that the most frequent cause of ear inflammation in dogs were Malassezia pachydermatis fungi in the auditory meatus. Another equally important factor causing the disease was Otodectes cynotis. Only few dogs with otitis externa were diagnosed for the presence of bacteria. It was found that some dog breeds, such as Labrador retriever, Golden retriever, German shepherd, Cocker spaniel or Yorkshire terrier, due to their anatomy are more susceptible to otitis externa episodes. The majority of the cases of dogs suffering from otitis externa appeared in the summer. The lowest percentage was recorded in the spring and autumn.
\end{abstract}

Key words: bacteria, dogs, fungi, otitis externa, parasites

\section{INTRODUCTION}

Otitis externa in dogs is manifested by pathogenic skin lesions of the external auditory meatus, caused by various etiological factors. According to numerous authors (Barrasa et al., 2000; Angus et al., 2002; Cole et al., 2004; Rougier et al., 2005; Cambell et al., 2010; Boda et al., 2011 ) otitis externa is present in $15-20 \%$ of dogs examined clinically, $50-68 \%$ of which suffer from chronic and recurring inflammation, that frequently causes damage to the eardrum and leads to simultaneous otitis media. The incidence of otitis externa varies depending on the age of a dog. The studies conducted by Topala et al. (2007), Mircean et al. (2008), Taszkun (2013a,b) shows that $10 \%$ to $16 \%$ of otitis externa cases occur in 1-year-old dogs, 
$44 \%$ to $60 \%$ in dogs $1-5$ years of age and $24 \%$ to $44 \%$ - in dogs older than 5 years. The incidence of otitis externa in dogs highly depends on the predisposing factors. They are commonly related to the breed as well as to the anatomy and physiology of the auditory meatus, or to susceptibility to the diseases and disorders in the course of which the otitis externa occurs secondarily (food intolerance, vesicular disease, keratosis disorders or hormonal disorders) (Angus et al., 2002; Graham-Mize \& Rosser, 2004; Ziółkowska \& Nowakiewicz, 2004). According to Logas et al. (1994), otitis externa is more common among the breeds with hanging auricle that causes poor ventilation of the auditory meatus and leads to higher ear moisture. This contributes to the bacterial growth and increases the bacteria development. However, Machicote Goth (2011) does not support the theory and disagrees with breed-related predispositions to otitis externa. Another factor that predisposes dogs to ear inflammation is dense hair at the entrance of the auditory meatus, that causes poorer drying, therefore the moisture inside the ear increases. Under such conditions the Pseudomonas and Proteus bacteria thrive effectively (Barrasa et al., 2000). Cerumen and other secretions accumulating on the hair can cause its clumping and clogging the canal. The removal of hair from the auditory meatus may reduce the moisture. Otitis externa also occurs in dogs with narrowed auditory meatus (Yorkshire terrier). This factor can contribute to inflammation as the meatus patency is reduced and the air flow is impeded. Another primary cause of otitis externa may be seborrhoeic dermatitis. The disease is rare in dogs, but its result is sebaceous gland disorder inside the auditory meatus. It was found to be a breed-related predis- position, inherited as an autosomal recessive trait (Zur \& Botero-Angus, 2011). The breeds predisposed to otitis externa include the Akita Inu and the Poodle (Reichler et al., 2001). Moreover, the weather conditions such as ambient temperature and air humidity, animal management and routines may affect the frequency of occurrence of otitis externa in dogs.

Views on the etiology of otitis externa are quite varied and intricate. Therefore, in the conducted research the most common causes of the disease, such as fungi, bacteria and parasites, including the predisposing factors, such as breed and the time of year were taken into account.

\section{MATERIALS AND METHODS}

The research was conducted in two veterinary clinics in Bydgoszcz. Data were collected in years 2011 and 2012. A total of $1,185 \mathrm{dogs}$ were registered, 121 of them were diagnosed with otitis externa. In every office the veterinary physician carried out detailed interviews with the owners of the dogs suspected to suffer from otitis externa, what aimed to determine the cause by describing the behaviour of the animals. The examination started with the healthy or less painful ear testing to avoid discouraging the animals. In the case of aggressive or very nervous dogs anaesthesia was used. During the examination, the veterinarians used an otoscope, which was an essential tool for the tests of the skin and ear discharge. This enabled the detection of foreign bodies and a pathological condition, based on the evaluation of ear discharge in the acoustic duct.

In case the presence of parasites was suspected, a microscopic examination was applied, what enabled the detection of 
potential parasites in the discharge collected. When the presence of fungi or bacteria was suspected, the cytological examination was applied, during which the material obtained was transferred to a glass slide and dried. The collected discharge from the ear canal was sent to a specialised laboratory in which culture and susceptibility testing was performed. The Giemza special staining method was used and the material was viewed under the microscope. The usage of these three basic tests made it possible to divide the examined dogs in the terms of cause of morbidity. The causes were divided into the separate groups such as Otodectes cynotis, Cheyletiella, fungi of Malassezia pachydermatis genus, Gram-positive and Gram-negative bacteria. As per the Grampositive bacteria Staphylococcus pseudintermedius, Staphylococcus aureus and Streptococcus were taken into account. As per the Gram-negative the considered genera were Pseudomonas, Proteus and Escherichia coli. In addition, the obtained results from veterinary clinics were analysed and rated in the terms of frequency of occurrence of otitis externa in the dogs, depending on the season of the year. The periods were divided according to the calendar: spring from 21 March to 21 June, summer from 22 June to 27 September, autumn from 28 September to 21 December, and winter from December 22 to March 20. It was also assumed which breeds were mostly predisposed to otitis externa.

\section{RESULTS}

As presented in Table 1 the most frequent cause of ear inflammation in dogs were Malassezia pachydermatis fungi found in 59 individuals, what equaled $48.6 \%$. Another equally important cause of otitis externa were parasites, mainly Otodectes cynotis, found in 45 (37.1\%) examined dogs. Only $2.5 \%$ (3 animals) of all diagnosed cases were due to another parasite Cheyletiella. The total percentage of dogs diagnosed with the presence of a parasite causing otitis externa was $39.7 \%$. Bacteria caused inflammation of the ear in $11.6 \%$ of the cases studied with Staphylococcus intermedius $(2.5 \%)$ and Pseudomonas $(2.5 \%)$ as most prevalent species. Other bacterial pathogens included Staphylococcus aureus, Streptococcus, Proteus and Escherichia coli, each of them responsible for $1.7 \%$ of all cases (Table 1 ).

Table 1. Percentage of otitis externa causes in examined dogs

\begin{tabular}{|c|c|c|c|c|}
\hline \multicolumn{3}{|c|}{ Otitis externa cause } & Number of & Percentage \\
\hline \multirow{2}{*}{ Parasites } & \multirow{2}{*}{\multicolumn{2}{|c|}{$\begin{array}{l}\text { Otodectes cynotis } \\
\text { Cheyletiella }\end{array}$}} & 45 & 37.1 \\
\hline & & & 3 & 2.5 \\
\hline Fungi & \multicolumn{2}{|c|}{ Malassezia pachydermatis } & 59 & 48.6 \\
\hline \multirow{6}{*}{ Bacteria } & \multirow{3}{*}{ Gram-positive } & Staphylococcus pseudintermedius & 3 & 2.5 \\
\hline & & Staphylococcus aureus & 2 & 1.7 \\
\hline & & Streptococus & 2 & 1.7 \\
\hline & \multirow{3}{*}{ Gram-negative } & Pseudomonas & 3 & 2.5 \\
\hline & & Proteus & 2 & 1.7 \\
\hline & & Escherichia coli & 2 & 1.7 \\
\hline \multicolumn{3}{|l|}{ Total } & 121 & 100.0 \\
\hline
\end{tabular}


Table 2. List of dog breeds with otitis externa

\begin{tabular}{lcccc}
\hline Breed & $\begin{array}{c}\text { Number of } \\
\text { registered } \\
\text { dogs }\end{array}$ & $\begin{array}{c}\text { Number of } \\
\text { diagnosed dogs }\end{array}$ & $\begin{array}{c}\text { Percentage of } \\
\text { otitis externa } \\
\text { within a breed }\end{array}$ & $\begin{array}{c}\text { Percentage of otitis } \\
\text { externa from the } \\
\text { breed vs all af- } \\
\text { fected dogs }\end{array}$ \\
\hline Beagle & 15 & 4 & 26.6 & 3.3 \\
Boxer & 35 & 2 & 5.7 & 1.7 \\
English cocker spaniel & 47 & 16 & 34.0 & 13.2 \\
Golden retriever & 46 & 9 & 19.6 & 7.4 \\
Wirehaired dachshund & 69 & 3 & 4.3 & 2.5 \\
Labrador retriever & 89 & 18 & 20.2 & 14.9 \\
Maltese & 12 & 4 & 33.3 & 3.3 \\
Mongrel & 465 & 22 & 4.73 & 18.2 \\
German shepherd & 90 & 8 & 8.8 & 6.6 \\
Pekingese & 13 & 1 & 7.7 & 1.7 \\
Bavarian Mountain & 10 & 2 & 20.0 & 1.7 \\
Hound & 23 & 2 & 8.7 & 1.7 \\
Poodle & 10 & 2 & 20.0 & 8.3 \\
Rottweiler & 73 & 10 & 13.7 & 1.7 \\
Shih tzu & 45 & 2 & 4.4 & 3.3 \\
Schnauzer & 15 & 4 & 26.6 & 9.9 \\
West Highland white & 128 & 12 & 9.4 & 100.0 \\
terrier & 1185 & 121 & 10.21 & \\
Yorkshire terrier & & & & \\
\hline Total & & & & \\
\hline
\end{tabular}

Table 2 shows 17 dog breeds with otitis externa. Labrador retrievers were the most frequently infected as 18 out of 89 dogs visiting the clinics showed symptoms of otitis externa, i.e. $20.2 \%$ of all tested Labradors and $14.9 \%$ of the entire registered population. Second came English cocker spaniels, with a prevalence of 16 otitis externa patients (34\%) out of 47 dogs. This group accounted for $13.2 \%$ of the total of registered dogs. Other frequently appearing breeds included the Yorkshire terrier, which constituted 9.9\%, Shih tzu (8.3\%), Golden Retriever (7.4\%) and German shepherd (6.6\%). Mixedbreed patients were $18.2 \%$.

The study analysed the influence of the seasons on the frequency of otitis externa in dogs (Fig. 1 and 2). It was ascertained that otitis externa incidence was the highest during the summer months (43\%), lower in the winter $(26.7 \%)$; the remaining $15.7 \%$ of all cases occurred in the autumn and $14 \%$ in the spring (Fig. 1). The most common cause in the summer were fungi, which were detected in $56 \%$ of the examined population during the period. In subsequent periods the incidence related to the presence of fungi decreased from $43.8 \%$ in the winter to $41.2 \%$ in the spring. Regarding parasites which were a common cause of otitis externa in examined dogs, we did not find any significant effect of the season, as during the summer the cause was registered in $41.5 \%$ of the examined cases, similar to that during the winter $(40.6 \%)$; whereas in the remaining months the incidence fluctuated between $36.8 \%$ in the autumn and $35.3 \%$ in the spring. Bacteria 


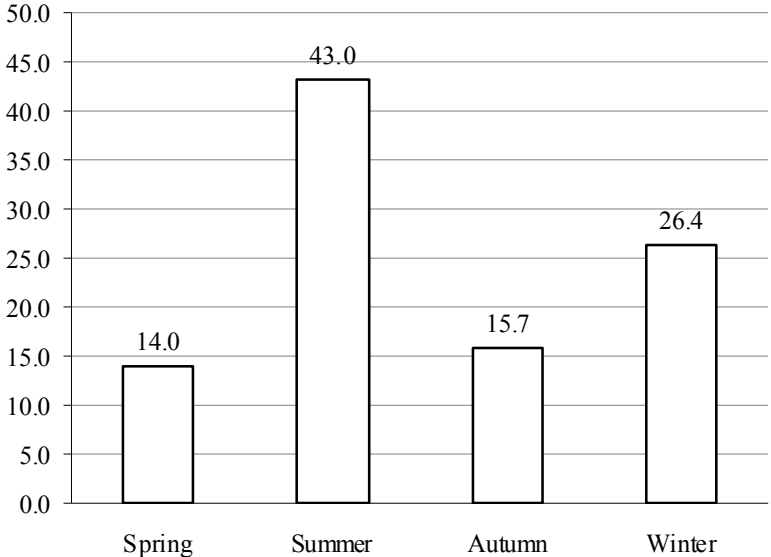

Fig. 1. Otitis externa cases in percentage terms depending on the season.

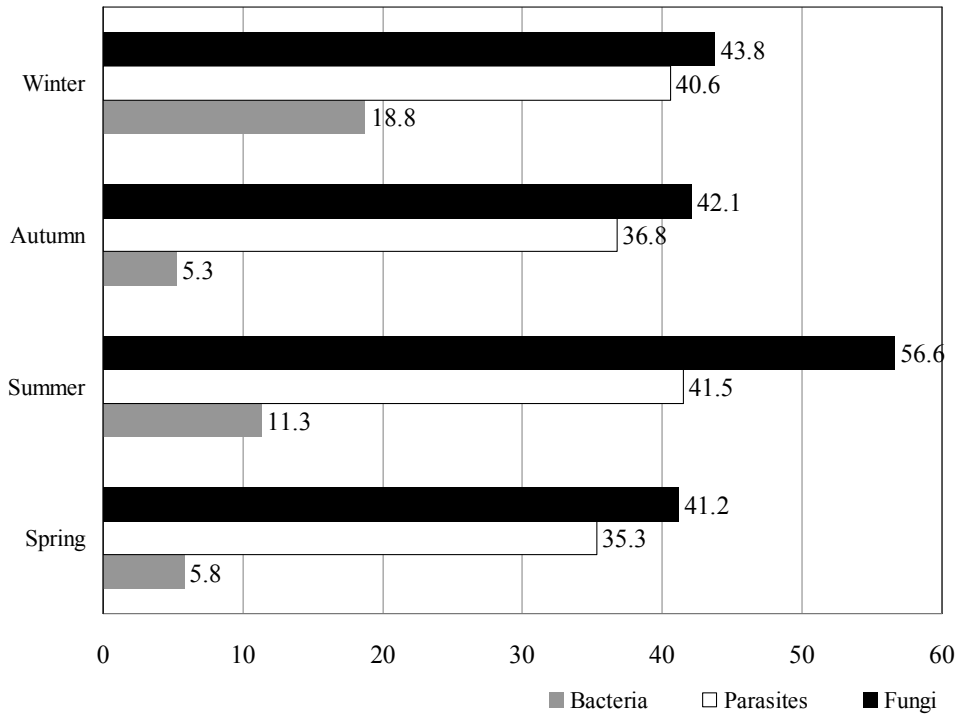

Fig. 2. Percentage of animals with otitis externa depending on the cause and season.

were the most common cause of otitis externa during the winter period $-18.8 \%$ of all analysed individuals. In the remaining periods, bacterial etiology attained $11.3 \%$ in the summer and above $5 \%$ in both spring and autumn (Fig. 2).

\section{DISCUSSION}

Our study showed that the most common cause of otitis externa in dogs were Malassezia pachydermatis fungi, which were found in 59 individuals, i.e. $48.6 \%$ 
of all dogs suffering from the disease. Sapierzyński (2009) confirmed the presence of the fungi in $68 \%$ of the affected dogs, whereas Mansfield et al. (1999), Ziółkowska \& Nowakiewicz (2004) as well as Bond et al. (1995) found in their studies on otitis externa that in $80-83 \%$ of the examined dogs the disease was caused by Malassezia fungi.

Otitis externa was frequently caused by parasites, mainly Otodectes cynotis found in 45 examined dogs $(37.1 \%)$ from the surveyed veterinary clinics. Another species: Cheyletiella, occurred only in 3 animals $(2.5 \%$ of all diagnosed cases) (Table 1). The total percentage of dogs diagnosed with a parasite causing otitis externa was $39.7 \%$. Sapierzyński (2009) stated in his research that parasites were present only in $10 \%$ of dogs with otitis externa. In this case alike, Otodectes cynotis was present in the majority of examined animals. The same author observed that the substantial majority of otitis externa cases related to parasites were diagnosed in young animals, less than one year old, as well as in old animals, older than 10 years. Similarly, Mircean et al. (2008) is of the opinion that otitis externa etiology changes depending on the age. The presence of parasites in both very young animals as well as older than 10 years was equal to $87.5 \%$. In the overall population study he found out that $26 \%$ of all animals were infected with parasites. The most common was Otodectes cynotis, at $69.23 \%$. In other works Otodectes cynotis caused otitis externa in 5-26\% of all affected dogs (Griffin et al., 1993; Mircean et al., 2008).

The cause of otitis externa related to the presence of bacteria in all analysed dogs was the lowest and included $11.6 \%$ of sick animals based on the total population analysed. The most frequent bacterial pathogens were Staphylococcus pseudintermedius (2.5\%) and Pseudomonas (2.5\%) followed by $S$. aureus, Streptococcus, Proteus and E. coli (1.7\%) of cases (Table 1). A similar percentage of bacterial infection in dogs with otitis externa was found by Sapierzyński (2009). In other studies the bacterial factor was responsible for $22.28 \%$ of otitis externa cases (Mircean et al., 2008).

In this study the most frequently infected was the Labrador retriever breed (20.2\% of all registered Labradors, and $14.9 \%$ of the entire registered population). The next breed on the list was the English cocker spaniel with 16 out of 47 registered dogs suffering from otitis externa. This group accounted for $13.2 \%$ of the total of registered dogs, and $34 \%$ of all English cocker spaniels. Other breeds with significant prevalence of the disease include the Yorkshire terrier $(9.9 \%)$, Shih tzu (8.3\%), Golden Retriever (7.4\%) and German shepherd (6.6\%). Only a few dogs of other breeds were diagnosed with otitis externa. It is worth mentioning the fact that $18.2 \%$ of mongrels also suffered from otitis externa. Similar observations were made by Sapierzański (2009), who found out that the largest group of affected dogs were mongrels $(22 \%)$. As per the percentage share of other breeds in his research it is as follows: Yorkshire terrier (12\%), Labrador retriever (11\%), German shepherd $(6 \%)$, Golden retriever $(5 \%)$. Similar results were obtained by Mircean et al. (2008). In the studies of these authors, the most commonly affected dogs were German shepherds $(20 \%)$, followed by mongrels (14\%), Labrador retrievers $(8 \%)$ and Yorkshire terriers $(2 \%)$. According to the numerous reports, the list of breeds suffering from otitis externa is quite extensive (Ginel et al., 2002; Topala et al., 2007; Taszkun, 2013a) with most 
commonly affected breeds such as the French and English bulldog, various terriers (chiefly the American Staffordshire terrier), Boxer, German shepherd, Dachshund, Labrador Retriever, Golden Retriever, Basset or Setter. These are the breeds with an increased number of sebaceous and ceruminous glands, which may cause moistening in the entire auditory meatus and lead to inflammations. Angus et al. (2002) reported that Cocker spaniels are more susceptible to otitis externa both in the primary and secondary form compared to other breeds. We also may assume that certain breeds are predisposed to otitis externa.

In our own research we ascertained that otitis externa incidence was the highest during the summer months (43\%), lower in the winter $(26.7 \%)$; followed by autumn (15.7\%) and spring (14\%) (Fig. $1)$. Such differences between the seasons may indicate that the environmental conditions also played a role in the incidence rate. Staroniewicz et al. (1995), as well as Ziółkowska \& Nowakiewicz (2004), indicate that a climate change, air humidity or the flowering of plants may have a decisive role in inflammations occurring in the auditory meatus; while Sapierzyński (2009) has ruled out the influence of the seasons on the frequency of otitis extrena. In his research, he demonstrated that the rate of affected dogs over the entire year was stable $(21.2 \%$ in the spring, $18.3 \%$ in the summer, $20.4 \%$ in the autumn and $20.3 \%$ in the winter). However, he assumed that with a longer observation period and a higher number of dogs, the results could reveal the influence of a season on ear diseases to a certain extent.

As to the relationship between the cause of otitis externa and the season (Fig. 2) we observed that the most common cause in the summer were fungi, detected in $56 \%$ of the examined population during the period. In subsequent periods the incidence related to the presence of fungi decreased from $43.8 \%$ in the winter to $41.2 \%$ in the spring. Regarding parasites which were the next common cause of otitis externa in the examined dogs, we did not find any significant effect of the season in terms of size and frequency, as the summer prevalence was $41.5 \%$ similar to that of winter prevalence $(40.6 \%)$; whereas in the remaining months the incidence fluctuated between $36.8 \%$ in the autumn and $35.3 \%$ in the spring. Bacteria as the least common cause of otitis externa were most commonly encountered in the winter (18.8\% of patients). The remaining cases were at the level of $11.3 \%$ in the summer and above $5 \%$ in both spring and autumn (Figure 2).

Changing the microclimatic conditions such as air temperature, humidity or rain/snow, creates a microenvironment inside the external auditory meatus, providing good conditions for replication of some microorganisms. In a hot or humid climate the external ear infection caused by Gram-negative bacteria is more common (Sapierzyński, 2009).

\section{CONCLUSIONS}

Summing up the results of our research it can be concluded that the most widespread cause of otitis externa in dogs was Malassezia pachydermatis fungi as well as Otodectes cynotis, while the least common cause was the presence of bacteria. Some breeds, such as Labrador retriever, Golden Retriever, German shepherd, Cocker spaniel or Yorkshire terrier, due to the anatomy or physiology of the auditory meatus, or their susceptibility to disease, which may lead to disorders of the external auditory meatus, display a 
predisposition to more frequent occurrence of ear inflammations. We observed that the highest otitis externa incidence in dogs was during the summer. The factor which was most frequently responsible for inflammation in the external auditory meatus was the presence of fungi. However, it should be remembered that the occurrence of otitis externa may be conditioned by all allergens or foreign bodies inside the ears. Very often, an inflammation of the ear may result from the combined effect of two or more etiological factors.

\section{REFERENCES}

Angus, J. C., C. Lichtensteiger, K. L. Cambell \& D. J. Schaeffer, 2002. Breed variations in histopathologic features of chronic severe otitis externa in dogs: 80 cases (1995-2001). Journal of the American Veterinary Medical Association, 221, 10001006.

Barrasa, L. M., P. L. Gomez \& Z. G. Lama, 2000. Antimicrobial susceptibility patterns of Pseudomonas strains isolated from chronic canine otitis externa. Journal of Veterinary Medicine B, 47, 191-196.

Boda, C., P. Liege \& C. A. Reme, 2011. Evaluation of owner compliance with topical treatment of acute otitis externa in dogs: A comparative study of two auricular formulations. International Journal of Applied Research in Veterinary Medicine., 9, 157-165.

Bond, R., L. E. Saijonmaa-Koulumies \& D. H. Lloyd, 1995. Population size and frequency of Malassezia pachydermantis at skin and mucosal sites on healthy dogs, Journal of Small Animal Practice, 36, 147-150.

Cambell, J. J., K. S. Coyner, S. C. Rankin, T. P. Lewis, A. E. Schick \& A. K. Shumaker, 2010. Evaluation of fungal flora in normal and diseased canine ears. Veterinary Dermatology, 21, 619-625.
Cole, L. K., 2004. Otoscorpic evaluation of the auditory meatus. Veterinary Clinics of North America: Small Animal Practice. 34, 397-410.

Dworecka-Kaszak, B., 2000. Zakażenia Malassezja pachydermatis u psów i kotów. Magazyn Weterynaryjny, Suplement „Koty", pp. 36-39.

Ginel, P., P. Lucens, J.C. Rodriguez \& J. Ortega, 2002. A semiquantitative cytology evaluation of normal and pathological samples from the external auditory meatus of dogs and cats. Veterinary Dermatology, 13, 151-158.

Graham-Mize, C. A. \& E. Rosser, 2004. Comparison of microbial isolates and susceptibility patterns from the external auditory meatus of dogs with otitis externa. Journal of the American Animal Hospital Association, 40, 102-108.

Griffin, C. E., K. W. Kwochka \& J. M. Mac Donald, 1993. Current Veterinary Dermatology. The Science and Art of Therapy. Mosby, St. Louis, pp. 245-264.

Logas, D. B., 1994. Diseases of the auditory meatus. Veterinary Clinics of North America, Small Animal Practice, 24, 905-919.

Machicote Goth, G., 2011. External ear disease in dogs and cats. Veterinary Focus, 21, 2-9.

Mansfield, P. D., T. R. Boosinger, M. H. Attleberger, 1999. Infectivity of Malassezia pachedermatis in the external auditory meatus of dogs. Journal of the American Animal Hospital Association, 26, 97-100.

Mircean, V., M. Mircean, R. Gavcea \& V. Cozma, 2008. Epidemiological aspects of otitis externa in dogs. Lucrări Ştiintifice Medicină Veterinară Timisoara, 41, 427 436.

Reichler, I. M., B. Hauser, I. Schiller, R. W. Dunstan, K. M. Credille, H. Binder, T. Glaus \& A. Susi, 2001. Sebaceous adenitis in the Akita: Clinical observations, histopathology and heredity. Veterinary Dermatology, 12, 243-253. 
Rougier, S., D. Borell \& S. Pheulpin, 2005. A comparative study of two antimicrobial/anti-inflammatory formulation in the treatment of canine otitis externa. Veterinary Dermatology, 16, 299-307.

Sapierzyński, R., 2009. Otitis externa in dogs. Medycyna Weterynaryjna, 65, 552-556.

Staroniewicz, Z., J. Król \& J. Cierpisz, 1995. Bacterial and mycologic flora in dogs with otitis externa. Medycyna Weterynaryjna, 51, 667-670.

Taszkun, I., 2013a. Study of external ear canal inflammation in dogs from the Lublin Region in the years 2007-2011. Medycyna Weterynaryjna, 69, 283-287.

Taszkun I., 2013b. Postepowanie diagnostyczne w przypadkach otitis externa u psów. Życie Weterynaryjne, 88, 281-285.

Topala, R., I. Burtan, M. Fantanaru, S. Ciobanu \& L. C. Butran, 2007. Epidemiological studies of otitis externa at carnivores. Lucrări Ştiintifice Medicină Veterinară Timisoara, 4, 647-651.

Ziółkowska, G. \& A. Nowakiewicz, 2004. Occurrence of the genus Malassezia yeasts in the external ear canal of dogs. Medycyna Weterynaryjna, 60, 310-313.
Zur, G. \& A. M. Botero-Angus, 2011. Severe ulcerative and granulomatous pinnal lesions with granulomatous adenitis in unrelated vizslas. Journal of the American Animal Hospital Association, 47, 455-460.

Paper received 03.04.2014; accepted for publication 13.06.2014

\section{Correspondence:}

Natasza Święcicka

Department of Sheep, Goat and Fur Bearing Animal Breeding

Faculty of Animal Breeding and Biology University of Technology and Life Sciences ul. Mazowiecka 28, 85-084 Bydgoszcz e-mail: swiecicka@utp.edu.pl 